\title{
SIMPANAN BERJANGKA PADA KSPPS BMT AMANAH UMMAH MENURUT FATWA DSN-MUI NO. 02 DAN 115
}

\author{
Ditta Ayu Kurniasari Ekawardhani \\ Departemen Ekonomi Syariah-Fakultas Ekonomi dan Bisnis-Universitas Airalngga \\ Email: ditta.ayu-13@feb.unair.ac.id \\ Dian Filianti \\ Departemen Ekonomi Syariah-Fakultas Ekonomi dan Bisnis-Universitas Airalngga \\ Email: dian.filianti@gmail.com
}

\begin{abstract}
:
This study aims to determine the application of Time Deposits in Sharia Financing Savings and Loan Cooperative (KSPPS) BMT According to Fatwa DSN-MUI No: 02 / DSN-MUI / IV / 2000 and Fatwa DSN-MUI No: 115 / DSN-MUI / IX /2017. In its application using mudharabah agreement that is a cooperation contract between capital owner and entrepreneur to develop a business. In the development of the number of members of the time deposits did not increase as other savings products. So that needed research on its application. The results of this study indicate that in KSPPS BMT Amanah Ummah East Java, the application of saving futures using mudharabah mutlaqah contract, while for members have given satisfaction and not yet attract other members to save their funds in time deposits. Implementation of the DSN-MUI fatwa No: 02 / DSN-MUI / IV / 2000 and the DSN-MUI fatwa No: 115 / DSN-MUI / IX / 2017 at KSPPS BMT Amanah Ummah East Java has conformed with Sharia principles.
\end{abstract}

\section{PENDAHULUAN}

BMT merupakan salah satu jenis lembaga keuangan non bank yang bergerak dalam skala mikro sebagaimana koperasi simpan pinjam (KSP). BMT merupakan lembaga keuangan berdasarkan prinsip syariah, selain itu juga dapat dikatakan sebagai lembaga swadaya masyarakat di bidang kevangan, hal ini disebabkan karena BMT tidak hanya bergerak untuk pengelolaan modal saja namun juga bergerak dalam pengumpulan zakat infaq shadaqah (Sudarsono, 2004:98).

BMT merupakan jawaban dari permasalahan yang tidak hanya mengatasi masalah pembiayaan, BMT diharapkan mampu mengedukasi masyarakat untuk gemar menabung. Menabung mendidik masyarakat untuk memikirkan jangka panjang kehidupan yang ingin dicapai dengan memanagesetiap dana yang dimilikinya. Berbagai macam produk yang ditawarkan oleh BMT akan langsung menyentuh pada aktifitas yang diperlukan oleh masyarakat, disamping itu sebagai lembaga intermediasi BMT harus mampu bersaing dengan lembaga keuangan sejenis maupun lembaga kevangan konvensional (Lisdawami, 2017:890).

Diantara sekian banyak KSPPS BMT yang berkembang di Indonesia, KSPPS BMT Amanah Ummah adalah salah satu lembaga pengelola keuangan syariah. yang mengeluarkan produk jasa keuangan berbasis syariah. Salah satu produk penghimpunan dana di KSPPS BMT Amanah Ummah adalah simpanan

1) Jurnal ini merupakan bagian dari SkripsiDitta AyU Kurniasari Ekawardhani, NIM: 041311433071 yang diuji pada tanggal 20 Juli 2018. 
berjangka. Simpanan berjangka termasuk dalam tabungan investasi dengan tujuan khusus dan dengan jangka waktu bulanan. Berbeda dengan produk simpanan berjangka yang ada di BMT lainnya yang termasuk dalam deposito, tetapi akad yang digunakan sama yaitumudharabah mutlaqah. Konsep Simpanan Berjangka di KSPPS BMT Amanah Ummah adalah sebagai simpanan untuk mengendalikan dan sebagai edukasi kepada anggota tentangcash flowdan perencanaankeuangan. Sistem bagi hasil profit sharing diterapkan untuk menghindari sistem bunga. Dan dengan menggunakan teknik saldo rata-rata dalam perhitungan bagi hasil nya.

Islam mensyariatkan akad kerjasamamudharabah untuk memudahkan orang yang memiliki harta namun tidak mampu mengelolanya dan ada juga orang yang tidak memiliki harta namun memiliki kemampuan untuk mengelola dan mengembangkannya. Maka syariat memperbolehkan kerja sama mudharabah agar masing-masing bisa saling mengambil manfaat diantara mereka.

Pada dasarnya, hukum Islam memperbolehkan akad mudharabah. Seperti yang tercantum pada dalil AlQur'an surat An-Nisa ayat 29, yang artinya, "Hai orang-orang yang beriman, janganlah kamu saling memakan harta sesamamu dengan jalan yang batil, kecuali dengan jalan perniagaan yang berlaku dengan suka sama-suka di antara kamu. Dan janganlah kamu membunuh dirimu. Sesungguhnya Allah adalah Maha Penyayang kepadamu".

Banyaknya produk sejenis yang dimiliki lembaga keuangan lain seperti Simpanan Mudharabah masih belum sepenuhnya mampu membuat masyarakat gemar menabung, karena banyaknya kendala seperti minimnya cabang, tidak adanya ATM, banyaknya masyarakat yang kurang mengerti tentang sistem bagi hasil serta keuntungan menggunakan akad mudharabah, kurangnya pengetahuan masyarakat tentang KSPPS BMT dan urgensi berinvestasi masih sangat terbatas membuat masyarakat seringkali terlihat masih khawatir dan ragu untuk berinvestasi pada KSPPS BMT karena terbatasnya pengetahuan terkait KSPPS BMT membuat orang enggan menabung dan berinvestasi pada KSPPS BMT.

Koperasi Simpan Pinjam Pembiayaan Syariah (KSPPS) BMT Amanah Ummah adalah salah satu lembaga yang sudah beroperasi sejak tahun 1995 hingga saat ini, pada tahun 2006 BMT Amanah Ummah resmi menjadi Koperasi Jasa Kevangan Syariah (KJKS) dan pada tahun 2016 mengalami perubahan bentuk badan hukum sesuai dengan keputusan Kementerian Koperasi maka Koperasi Jasa Keuangan Syariah (KJKS) Amanah Ummah berubah nama menjadi Koperasi Simpan Pinjam dan Pembiayaan Syariah (KSPPS) BMT 
Amanah Ummah. Hal ini dilakukan dalam rangka menghimpun dan menyalurkan dana-dana bisnis dan sosial. KSPPS menjalankan peran ganda yaitu sebagai lembaga bisnis (tamwil) dan di sisi lain melakukan fungsi sosial yakni menghimpun, mengelola dan menyalurkan dana zakat, infaq. Shodaqoh, dan wakaf atau ZISWAF.

Koperasi Simpan Pinjam Pembiayaan Syariah (KSPPS) BMT Amanah Ummah sebagai lembaga Syariah yang mendapat sambutan positif dari berbagai kalangan masyarakat. Terbukti dari pertumbuhan kantor cabang KSPPS BMT Amanah Ummah yang terdapat 3 kantor kas di Surabaya, 1 kantor pusat Surabaya dan 1 kantor cabang Sidoarjo. Dengan jumlah pertumbuhan kantor kas ini, membuktikan bahwa KSPPS BMT Amanah Ummah cukup tumbuh dengan signifikan.

Simpanan berjangka ini memberikan pilihan kepada anggota untuk menabung dalam jangka pendek maupun jangka panjang sesuai dengan kebutuhan masing-masing. Anggota juga dapat memilih bagi hasil yang ingin didapatkan sesuai dengan pilihan simpanan yang dipilih.

Semakin lama jangka waktu yang dipilih dapat memberikan bagi hasil yang lebih tinggi. Sistem bagi hasil simpanan berjangka yang diterapkan oleh BMT memang memberikan keuntungan yang cukup tinggi. Namun hal ini juga tidak lepas dari permasalahan yang dihadapi BMT yaitu masih banyaknya masyarakat yang kurang mengerti tentang sistem bagi hasil serta keuntungan dengan menggunakan akad mudharabah.

Masyarakat yang sudah menjadi anggota di KSPPS BMT juga tidak begitu memahami terkait pelaksanaan mudharabah pada simpanan berjangka tentang pengelolaan dana nya dan bagi hasil yang didapatkan. Menurut kesaksian beberapa anggota dalam wawancara pada penelitian terdahulu, para anggota tidak begitu memikirkan kemana dana investasi simpanan berjangka mereka dialokasikan untuk dikelola. Hal ini sebenarnya sah-sah saja karena mudharabah mutlaqah merupakan akad yang membebaskan mudharib untuk mengelola dana investasi simpanan berjangka shahibul maal dengan sebebas-bebasnya, selama tidak bertentangan dengan prinsip syariah.

Ketentuan mengenai pelaksanaan simpanan berjangka yang dilakukan oleh KSPPS BMT Amanah Ummah perlu ditinjau dari segi fatwa DSN-MUI sebagai aturan syariah untuk semua kegiatan ekonomi pada lembaga kevangan syariah. Salah satu fatwa DSN-MUI yang memutuskan mengenai pelaksanaan penerapan akad mudharabah adalah fatwa fatwa DSNMUI No. 115 tahun 2017 dan fatwa DSN-MUI No. 02 tahun 2000 tentang tabungan, praktik akad mudharabah terkait kegiatan usaha atau bisnis dan 
tabungan yang berdasarkan prinsip mudharabah serta sistem bagi hasil simpanan berjangka yang diterapkan oleh KSPPS BMT Amanah Ummah.

Keseluruhan

pelaksanaan

simpanan berjangka perlu diteliti mengenai pelaksanaan simpanan berjangka yang sesuai dengan fatwa DSN-MUI hingga berbagai kebijakan yang dilakukan oleh KSPPS BMT Amanah Ummah untuk pelaksanaan simpanan berjangka yang sudah sepenuhnya dijalankan. Beberapa hal yang perlu ditelaah lagi yaitu mengenai ketentuan pelaksanaan simpanan berjangka, pengelolaan dana, bagi hasil yang diperoleh dan penyelesaian akad. Sehingga hal tersebut perlu ditelaah apakah prosedur simpanan berjangka sudah sesuai dengan aturan syariah yaitu fatwa DSN-MUI.

Kesesuaian syariah merupakan pedoman lembaga keuangan syariah dalam melakukan operasional keseluruhan lembaga. Dengan sudah sesuaianya operasional yang dilakukan oleh lembaga keuangan syariah maka hal tersebut dapat meningkatkan kepercayaan nasabah untuk menggunakan produk dan jasa layanan dari lembaga keuangan tersebut. Selain itu, lembaga keuangan syariah mampu meningkatkan citra baik kepada masyarakat.

\section{LANDASAN PUSTAKA}

Baitul Maal Wat Tamwil (BMT) di artikan sebagai lembaga keuangan non profit dan lembaga keuangan profit. Perbedaan pengertian antara Baitul Maal dan Baitul Tanwil, yaitu Baitul Maal lebih mengarah pada usaha-usaha pengumpulan dan penyaluran dana yang non profit seperti zakat, infaq dan shadaqah. Demikian juga terkait dengan pengembangan wakaf tunai. Sedangkan Baitul Tanwil sebagai usaha pengumpulan dan penyaluran dana komersial (Sudarsono, 2003:4).

Secara kelembagaan BMT didampingi atau didukung Pusat Inkubasi Bisnis Usaha Kecil (PINBUK). Definisi BMT menurut operasional PINBUK dalam peraturan dasar yakni "Baitul Maal Wat Tamwil adalah suatu lembaga ekonomi rakyat kecil yang berupaya mengembangkan usahausaha produktif dan investasi dalam meningkatkan kegiatan ekonomi pengusaha kecil bawah berdasarkan prinsip syariah dan prinsip koperasi" (Sudarsono, 2004:96).

Dari penjelasan diatas dapat disimpulkan bahwa, pengertian Baitul Maal Wat Tamwil adalah sebagai lembaga keuangan non bank dengan kegiatan dan fungsi bisnis yaitu untuk mengembangkan usaha produktif dan menghimpun dana dari masyarakat terutama untuk usaha kecil, serta fungsi sosial yaitu menerima titipan zakat, infaq dan shadaqah serta menyalurkannya sesuai dengan prinsipprinsip Islam.

Mudharabah adalah suatu kerjasama antara dua pihak dimana 
pihak shahibul maal (pemilik dana) dan mudharib (pengelola dana) yang bertanggung jawab atas pengelolaan usaha. Hasil usaha ini akan dibagi hasilkan berdasarkan nisbah bagi hasil yang disepakati. Namun bila terjadi kerugian karena kelalaian dan kecurangan pengelola maka akan ditanggung oleh pengelola dana sepenuhnya (Sudarsono, 2004:59).

$$
\text { Menurut Ascarya (2007:60) sebagai }
$$

suatu bentuk kontrak, mudharabah merupakan akad bagi hasil ketika pemilik dana/modal (pemodal), biasa disebut shahibul maal/rabbul maal, menyediakan modal (100 persen) kepada pengusaha sebagai pengelola, biasa disebut mudharib, untuk melakukan aktivitas produktif dengan syarat bahwa keuntungan yang dihasilkan akan dibagi di antara mereka menurut kesepakatan yang ditentukan sebelumnya dalam akad (yang besarnya juga dipengaruhi oleh kekuatan pasar).

Dalam Islam akad mudharabah dibolehkan, karena bertujuan untuk saling membantu antara rabb al-mal (investor) dengan pengelola dagang (mudharib). Landasan dasar pembiayaan mudharabah lebih mencerminkan anjuran untuk melakukan usaha (Antonio, 2008:95) yang dijelaskan dalam Al-Qur'an Surat Al-Baqarah ayat 198:
Laisa 'alaikum junăhun an tabtagĭ fadlam mir rabbikum, fa izä

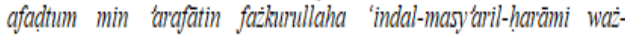
kuruihu kamā hadäkum, wa in kuntum min qablihi laminad-dälliñ. Artinva: "Tidak ada dosa bagimu untuk mencari karunia (rezki hasil perniagaan) dari Tuhammu. Maka apabila kamu telah bertolak dari 'Arafat, berdzikirlah kepada Allah di Masy'arilhar' (Ialah bukit Quzah di Mirdalifah).Dan berdikirlah (dengan mervebut) Allah sebagaimana yang ditunjukkan-Nya kepadamu; dan Sesingguhnya kamu sebelum itu benar-benar Termasuk orang-orang yang sesat" (Q.S. Al-Baqarah:198).

Beberapa fatwa DSN yang mengatur akad mudharabahantara lain adalah:

Fatwa DSN-MUI No: 115/DSNMUI/IX/2017 tentang akad Mudharabah.

Fatwa ini menjelaskan tentang bagaimana praktik akad mudharabah terkait kegiatan usaha atau bisnis untuk perbankan, perusahaan pembiayaan, jasa keuangan maupun aktivitas bisnis lainnya. Mudharabah adalah akad kerjasama suatu usaha antara dua pihak di mana pihak pertama (shahibul maal) menyediakan seluruh modal, sedangkan pihak kedua pengelola (mudharib) bertindak sebagai pengelola. Keuntungan usaha dibagi sesuai dengan kesepakatan.

a. Fatwa DSN-MUI No: 02/DSNMUI/IV/2000 tentang Tabungan

Fatwa ini memutuskan bahwa tabungan ada dua jenis yaitu, (1) tabungan yang tidak dibenarkan secara syariah, yaitu tabungan yang berdasarkan perhitungan bunga, dan (2) tabungan yang dibenarkan, yaitu tabungan yang berdasarkan prinsip Mudharabah dan Wadi'ah.

Rukun dari akad mudharabah yang harus dipenuhi dalam transaksi ada beberapa, yaitu: 
1. Pelaku akad, yaitu shahibul maal (pemodal) adalah pihak yang memiliki modal tetapi tidak bisa berbisnis, dan mudharib (pengelola) adalah pihak yang pandai berbisnis, tetapi tidak memiliki modal.

2. Objek akad, yaitu modal (maal), kerja (dharabah), dan keuntungan (ribh)

3. Shighah, yaitu ljab dan Qabul.

Secara umum mudharabah terbagi menjadi dua jenis yaitu (Sudarsono, 2004:59-60) :

Al-Mudharabah Mutlaqah adalah bentuk kerjasama antara shahibul maal dan mudharib yang cakupannya sangat luas dan tidak dibatasi spesifikasi jenis usaha, waktu dan daerah bisnis.

Al-Mudharabah

Muqayyadah

(restricted mudharabah atau specified mudharabah) adalah bentuk kerjasama antara shahibul maal dan mudharib yang cakupannya mudharib dibatasi dengan batasan usaha, waktu dan tempat usaha. Dan adanya pembatasan ini seringkali mencerminkan kecenderungan umum shahibul maal dalam memasuki jenis usaha.

\section{METODE PENELITIAN}

\section{Pendekatan penelitian}

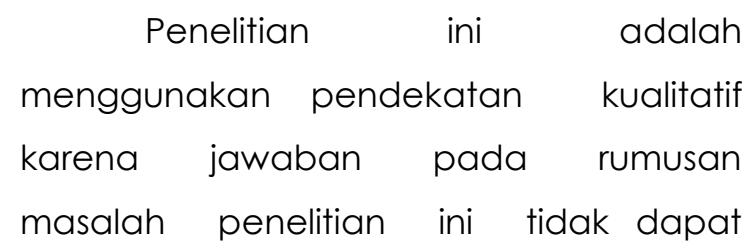

diperoleh dengan cara menggunakan prosedur-prosedur statistik.

Penelitian dengan pendekatan penelitian kualitatif merupakan penelitian yang bermaksud untuk memahami fenomena tentang apa yang dialami oleh subjek penelitian misalnya, penerapan, motivasi, tindakan, dan lain-lain secara holistik dan dengan cara deskripsi dalam bentuk kata-kata dan bahasa, pada suatu konteks khusus yang alamiah dan dengan memanfaatkan berbagai metode penelitian Moleong (2011:6). Dalam penelitian ini menggunakan pendekatan kualitatif karena pertimbangan bahwa perlu adanya pendekatan secara langsung antara peneliti dan informan sehingga dapat mengungkap secara lengkap dan memahami fenomena penerapan simpanan berjangka menurut fatwa DSN-MUI pada KSPPS BMT Amanah Ummah yang sesuai dengan prinsip syariah.

\section{Ruang Lingkup Penelitian}

Batasan ruang lingkup penelitian ini berdasarkan rumusan masalah yang akan diteliti yaitu bagimana kesesuaian penerapan simpanan berjangka menurut fatwa DSN-MUI di KSPPS BMT Amanah Ummah sudah sesuai dengan ketentuan syariah. Penelitian ini akan menjelaskan tentang aturan-aturan syariah dari praktik akad pada simpanan berjangka menurut fatwa DSN-MUI dan membandingkan dengan realisasi yang ada di lapangan. Penulis 
akan menjelaskan tentang sudah atau belum sepenuhnya dijalankan penerapan simpanan berjangka menurut fatwa DSN-MUI yang dimiliki oleh KSPPS BMT Amanah Ummah.

\section{Jenis dan Sumber Data}

Data primer dalam penelitian ini berasal dari informan kunci dan informan tambahan. Dalam penelitian ini ada tiga narasumber yang menjadi informan kunci, yaitu pengurus KSPPS BMT Amanah Ummah Jawa Timur, selaku pihak yang bertamggung jawab akan keseluruhan operasional transaksi yang ada di KSPPS BMT Amanah Ummah. Kemudian yang menjadi informan tambahan dalam penelitian ini, yaitu Customer Service kantor KSPPS BMT Amanah Ummah Jawa Timur, karena merupakan pihak yang langsung menerangkan dan mempraktikkan operasional produk dan transaksi yang ada di KSPPS BMT.

Data sekunder merupakan data yang mendukung penelitian, yang didapatkan secara tidak langsung dari suatu objek penelitian. Data sekunder dalam penelitian ini diperoleh dari anggota produk simpanan berangka di KSPPS BMT Amanah Ummah Jawa Timur, jurnal, artikel atau buku-buku yang dapat dijadikan refrensi bagi peneliti tentang mudharabah simpanan berjangka pada KSPPS BMT, dan dokumen atau laporan kegiatan penelitian yang pernah dilakukan yang terkait dengan produk simpanan berjangka pada KSPPS BMT.

\section{Unit Analisis}

Dalam penelitian ini, unit analisis adalah pada KSPPS BMT Amanah Ummah Jawa Timur, dengan kasus penerapan simpanan berjangka sesuai dengan ketentuan syariah.

Pemilihan unit analisis tersebut dikarenakan peneliti ingin meniliti lebih dalam mengenai pelaksanaan simpanan berjangka yang termasuk didalamnya adalah penggunaan akad, syarat dan ketentuan, keuntungan yang didapat dan perhitungan bagi hasil yang didapat.

\section{Pengumpulan Data}

Langkah-langkah memperoleh data yang digunakan adalah sebagai berikut:

a. Menyelesaikan birokrasi dan surat ijin penelitian pada Fakultas Ekonomi DanBisnis Universitas Airlangga.

b. Mendatangi objek penelitian dan melakukan wawancara terhadap informan terkait.

\section{Teknik Analisis Data}

Dalam penelitian ini, peneliti menggunakan teknik analisis penjodohan pola. Penjodohan pola bertujuan untuk membandingkan hasil temuan kepada pihak KSPPS BMT Amanah Ummah Jawa Timur dengan prinsip syariah.

Pembahasan dilakukan dengan cara mengetahui pelaksanaan Simpanan Berjangka pada KSPPS BMT Amanah Ummah Jawa Timur. Bagaimana penerapan simpanan berjangka menurut fatwa DSN-MUI, apakah sudah sesuai 
syariah sehingga dapat sejalan dengan prinsip muamalah dalam Islam.

\section{HASIL DAN PEMBAHASAN}

Operasional penerapan akad Simpanan Berjangka berdasarkan pada akad mudharabah yang mana disesuaikan dengan fatwa DSN-MUI mengenai pelaksanaan praktik akad mudharabah. Simpanan Berjangka merupakan tabungan dengan jangka waktu yang berdasarkan dengan akad mudharabah mutlaqah.

Berikut merupakan hasil penerapan Simpanan Berjangka pada KSPPS BMT Amanah Ummah dengan aturan fatwa DSN-MUI:

1. Penerapan dengan fatwa DSNMUI No: 02/DSN-MUI/IV/2000 tentang Tabungan.

Pada fatwa ini, dijelaskan lebih lanjut mengenai aturan dalam menghimpun dana dari masyarakat oleh lembaga keuangan. Tabungan yang berdasarkan perhitungan bunga tidak diperbolehkan, tabungan yang diperbolehkan menggunakan bagi hasil. Maka dari itu tidak semua kegiatan tabungan dibenarkan oleh hukum Islam (syariah).

Menurut informan, simpanan berjangka pada KSPPS BMT Amanah Ummah tidak menerapkan sistem bunga dan menghindarkan praktek riba dengan menggunakan modal dalam bentuk tunai dan nisbah bagi hasil dituangkan dalam akad pembukaan rekening. Hal ini sesuai dengan ketentuan umum pada fatwa yaitu bahwa lembaga keuangan harus melaksanakan transaksi yang bebas riba dan tabungan yang dibenarkan yaitu tabungan yang berdasarkan prinsip mudharabah dan wadi'ah. Simpanan berjangka pada KSPPS BMT Amanah Ummah melakukan penghimpunan dananya (tabungan) dengan menggunakan akad mudharabah mutlaqah dan dikelola berdasarkan prinsip kehati-hatian, maqasyid dan mematuhi syariah complient yang sudah ditetapkan.

Pada awal permohonan untuk menjadi anggota (nasabah), anggota dijelaskan terlebih dahulu beberapa persyaratan oleh KSPPS BMT Amanah Ummah di mana salah satunya adalah anggota memberi kekuasaan penuh kepada KSPPS BMT Amanah Ummah untuk mengelola dana/menginvestasikan. Dan anggota tidak memberikan batasan atau syarat tentang barang serta jenis usaha. Hal ini disesuaikan pula pada ketentuan fatwa yang menyebutkan bahwa lembaga keuangan dapat melakukan berbagai macam usaha yang tidak bertentangan dengan prinsip syariah.

Pembagian keuntungan didasarkan pada profit sharing dan revenuesharing dari dana yang di investasikan, jadi keuntungan bagi hasil yang didapatkan tidak selalu stabil tetapi sesuai dengan kondisi usaha. Prosentase nisbah bagi hasil harus dijelaskan diawal kesepakatan. Jangka waktu yang dipilih mempengaruhi prosentase bagi hasil yang didapatkan. 
Tidak ada kerugian dalam simpanan berjangka hanya nominal bagi hasilnya yang turun. Dalam pengelolaannya KSPPS BMT Amanah Ummah tidak bekerjasama dengan lembaga kevangan lain, dana simpanan berjangka dikelola sendiri sebagai pembiayaan.

Penarikan sebelum jatuh tempo tidak diperbolehkan, karena sudah adanya kesepakatan pengambilan dana nya sesuai dengan jatun tempo dan tidak ada sanksi yang diberikan kepada anggota yang menarik dananya sebelum jatuh tempo. Untuk meminimalisir kerugian pengelolaan dana simpanan berjangka yang terjadi di KSPPS BMT Amanah Ummah yaitu dengan lebih selektif dalam pemberian pembiayaan kepada anggota, terutama harus tertib administrasi sesuai dengan SOP yang sudah diterapkan.

$\begin{array}{clr}\text { Dari } & \text { keseluruhan analisis } \\ \text { pelaksanaan } & \text { Simpanan Berjangka }\end{array}$ sebagai tabungan pada KSPPS BMT Amanah Ummah dinyatakan sudah $100 \%$ sesuai dengan fatwa DSN-MUI No: 02/DSN-MUI/IV/2000 tentang Tabungan.

Penerapan dengan fatwa DSN-MUI No: 115/DSN-MUI/IX/2017 tentang akad mudharabah.

Simpanan Berjangka merupakan tabungan yang berdasarkan akad mudharabah. Pada akad ini, dilakukan peninjauan mengenai praktik pelaksanaan mudharabah pada simpanan berjangka yang dilaksanakan oleh KSPPS BMT Amanah Ummah.
Praktik tersebut antara lain dari cara pengelolaan dana, perolehan keuntungan, dan ketentuan penyelesaian akad.

Simpanan Berjangka di KSPPS BMT Amanah Ummah menggunakan akad mudharabah mutlaqah, dalam akad tersebut shahibul maal (anggota) harus memberikan kebebasan kepada mudharib (KSPPS BMT) untuk mengelola dana simpanan berjangka tersebut. Menurut Ibu Linake Septi Elfianti sebagai informan bahwa penerapan akad mudharabah yaitu kerjasama mudharabah di berjangka sendiri dan ada tempo 1 bulan 3 bulan dan sampai 12 bulan, disitu otomatis kita melakukan simpanan mudharabah dari tata laksana yang sesuai dengan tempo tersebut dan dana nya dialokasikan di sektor mikro sesuai tempo yang dikehendaki. Jadi pada saat anggota menarik dana nya tersebut dana itu sudah tersedia di kita.

Pengelolaan dana simpanan berjangka di KSPPS BMT Amanah Ummah tidak bekerjasama dengan lembaga keuangan lain, dana simpanan berjangka dikelola sendiri. Pengelolaan dana simpanan berjangka di salurkan pada pembiayaan yang ada di KSPPS BMT Amanah Ummah. Sudah adanya ketentuan prosentase yang didapatkan antara anggota dengan KSPPS BMT dan ketentuan tersebut dilakukan pada saat awal kesepakatan akad. 
Menurut Bapak Drs. H. M. Shufyan Bahri, MPSDM sebagai sekretaris pengurus di KSPPS BMT Amanah Ummah mengatakan bahwa insyaAllah tidak ada rugi dalam simpanan berjangka, hanya nominal bagi hasilnya saja yang turun. Maka dari itu KSPPS BMT Amanah Ummah sangat meminimalisir kerugian yang akan terjadi dari pengelolaan dana simpanan berjangka dengan cara selektif dalam melakukan penyaluran pembiayaan kepada anggota. Agar tidak terjadi kerugian antara anggota dan KSPPS BMT Amanah Ummah.

$$
\text { Penyelesaian akad pada }
$$
simpanan berjangka yaitu dari pihak KSPPS BMT Amanah Ummah akan memberikan informasi kepada anggota jika sudah jatuh tempo pengambilan dana nya mau di ARO (Automatic Roll Over) dihentikan. Jika dihentikan langsung melakukan penarikan dan membawa persyaratan yang sesuai dengan syarat-syarat yang ada.

Pada analisis penerapan di atas, penerapan Simpanan Berjangka dengan akad mudharabah pada KSPPS BMT Amanah Umah sudah $100 \%$ sesuai syariah. penjodohan kesesuaian antara fatwa dan pelaksanaan yang ada di KSPPS BMT Amanah Ummah menunjukkan beberapa hal yang perlu diperhatikan sehingga pelaksanaan Simpanan Berjangka tidak melenceng dari aturan syariah.

\section{SIMPULAN}

Berdasarkan hasil dari pembahasan sebelumnya dapat disimpulkan bahwa Penerapan Simpanan Berjangka menggunakan akad mudharabah mutlaqah, dimana shahibul maal (anggota) membebaskan mudharib (KSPPS BMT Amanah Ummah) untuk melakukan usaha apapun yang sesuai dengan prinsip syariah.

1. Simpanan Berjangka bukan merupakan deposito, tetapi tabungan investasi dengan jangka waktu.

2. Penerapan simpanan berjangka telah sesuai dengan syariah $\mathrm{Hal}$ ini didasarkan dengan fatwa DSN-MUI No. 115 tentang akad mudharabah dan fatwa DSNMUI No. 02 tentang tabungan

\section{DAFTAR PUSTAKA}

Al Qur'an dan Terjemahannya. 2014. Jakarta:Kementrian Agama RI.

Ascaraya. 2008. Akad dan Produk Bank Syariah. Jakarta: PT Raja grafindo Persada.

Fatwa DSN MUI No.02/DSNMUI/IV/2000 Tabungan.

Fatwa DSN MUI No. 115/DSNMUI/IX/2017 Akad Mudharabah.

Karim, Adiwarman. 2010. Bank Islam: Analisis Fiqih dan Keuangan, Edisi 4. Jakarta: PT. Raja Grafindo Persada.

Lisdiwami, Indi Masita. Pengembangan Produk Funding KSPPS BMT Amanah Ummah Jawa Timur. Surabaya: Jurnal Ekonomi Syariah Teori dan Terapan 
Ekawardhani, et al/Jurnal Ekonomi Syariah Teori dan Terapan Vol. 6 No. 1 Januari: 59-69; SIMPANAN BERJANGKA PADA KSPPS BMT AMANAH UMMAH MENURUT FATWA DSN-MUI NO. 02 DAN 115

Moleong, Lexy J.2011. Metodologi

Penelitian Kualitatif. Bandung: Remaja

Rosdakarya.

Sudarsono, Heri.2004. Bank dan Lembaga Kevangan Syariah. Yogyakarta: Ekonisia.

Yin, Robert K.2014. Studi Kasus: Desain \& Metode. Jakarta: Grafindo. 